\title{
Combination of search, coagulation, clipping, and polyglycolic acid sheet to prevent delayed bleeding after gastric endoscopic submucosal dissection
}

The search, coagulation, and clipping method is reported to be significantly better than the existing approache in the prevention of delayed bleeding after gastric endoscopic submucosal dissection (ESD). However, it does not completely prevent post-ESD bleeding [1]. Another method combines the use of polyglycolic acid (PGA) sheets and fibrin glue to reduce the risk of delayed bleeding after gastric ESD [2], but a multicenter, prospective, randomized controlled study showed that use of PGA sheets alone was not effective in preventing delayed bleeding in patients at high risk for such bleeding [3]. We hypothesized that delayed bleeding could be prevented by combining the use of PGA sheets and fibrin glue with a modified search, coagulation, and clipping method that accommodates patients at high risk of delayed bleeding. Here we report on the prevention of delayed bleeding using this new combined approach.

First, a coagulation procedure was performed after lesion resection, mainly in the vessels at the margin of the ulcer base. Then, perforator vessels emerging between muscle layers were actively sought and clipped using hemoclips. Because perforator vessels may also be present in carbonized areas of the ulcer base, clipping was also actively performed in such areas; this constituted the modification of the search, coagulation, and clipping method (\$ Fig.1). Subsequently, several large and small PGA sheets were placed (based on the size of the ulcer base), using methods proposed by Kobayashi et al. [4] and Takimoto et al. [5], respectively. Finally, fibrin glue was sprayed ( $\triangleright$ Fig. 2). All these steps constitute the polyglycolic acid sheets, fibrin glue, and modified search, coagulation, and clipping method (PMSCC) method.

- Video 1 shows application of the PMSCC method in a 74-year-old man classified as having high risk of delayed bleeding because of oral warfarin administration. The ulceration followed gastric ESD (40 $\mathrm{mm}$ in diameter) in the posterior wall of the lesser curvature of the middle body of the stomach. We implemented the PMSCC method in nine patients at high risk of delayed bleeding. None of the nine patients experienced delayed bleeding.

Although bleeding may be observed from perforator vessels in areas where PGA sheets are peeled off [3], we believe that if perforator vessels at the base of ulcers are clipped in advance then such delayed bleeding may be prevented.

Endoscopy_UCTN_Code_TTT_1AO_2AD

\section{Competing interests}

The author declares no conflict of interest.

The authors

Satoshi Abiko, Ayumu Yoshikawa, Kazuaki Harada, Naoki Kawagishi, Itsuki Sano, Hisashi Oda, Takuto Miyagishima

Department of Gastroenterology, Kushiro Rosai Hospital, Kushiro, Japan
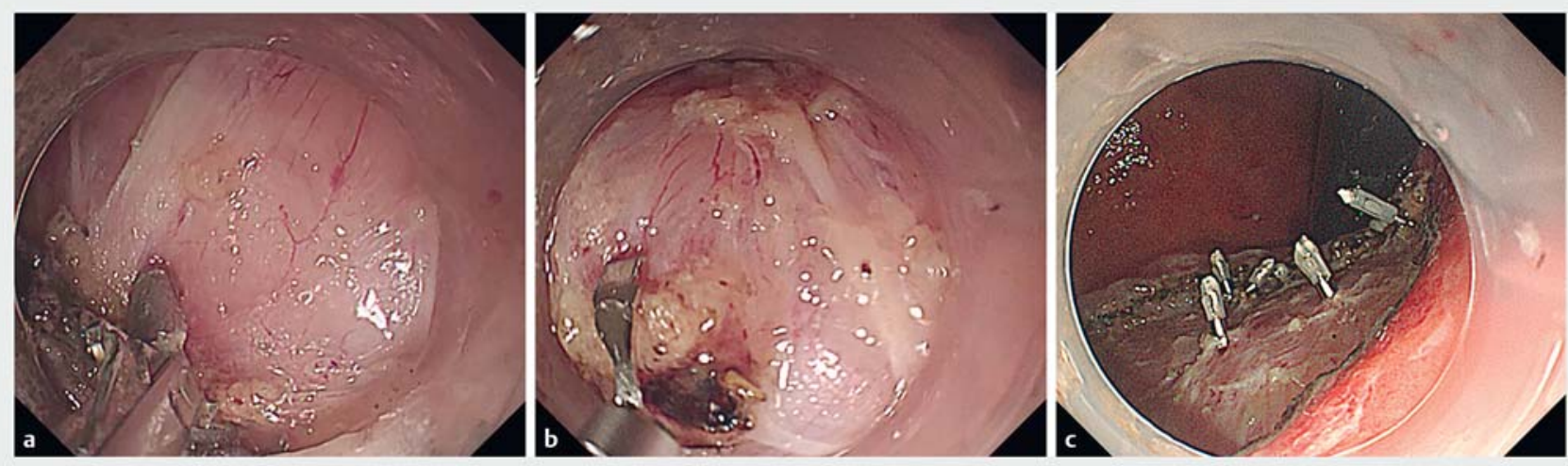

- Fig. 1 A modified search, coagulation, and clipping method for preventing delayed bleeding after gastric endoscopic submucosal dissection. a First, a coagulation procedure was done after lesion resection, mainly in the vessels at the margin of the ulcer base. b Perforator vessels may also be present in carbonized areas of the ulcer base. Clipping was also actively performed in such areas, which is the modification of the search, coagulation, and clipping approach. c The modified approach was completed. 

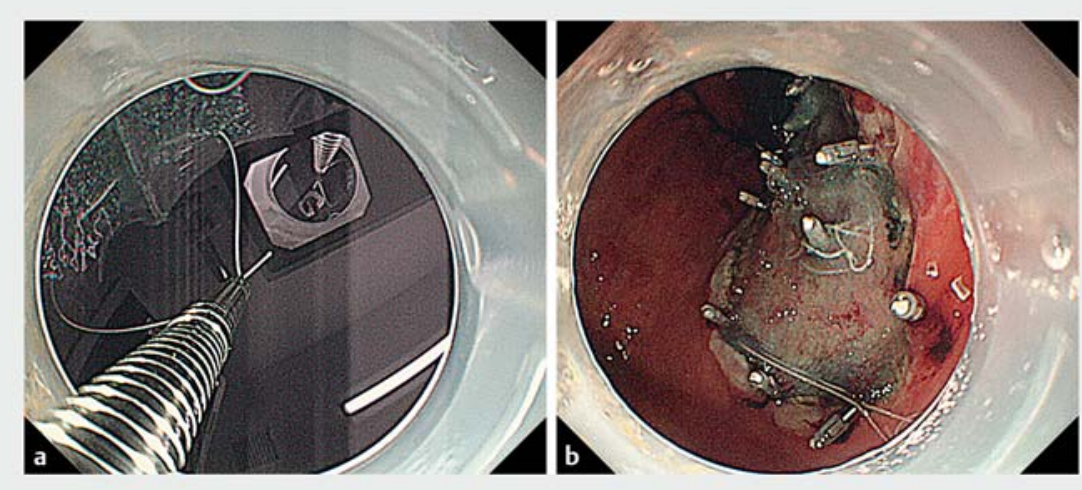

- Fig. 2 Use of polyglycolic acid (PGA) sheets and fibrin glue after the modified search, coagulation, and clipping method. a Large PGA sheets were placed using a wafer paper, thread, and hemoclip.b Completion of the polyglycolic acid sheets, fibrin glue, and modified search, coagulation, and clipping (PMSCC) method.

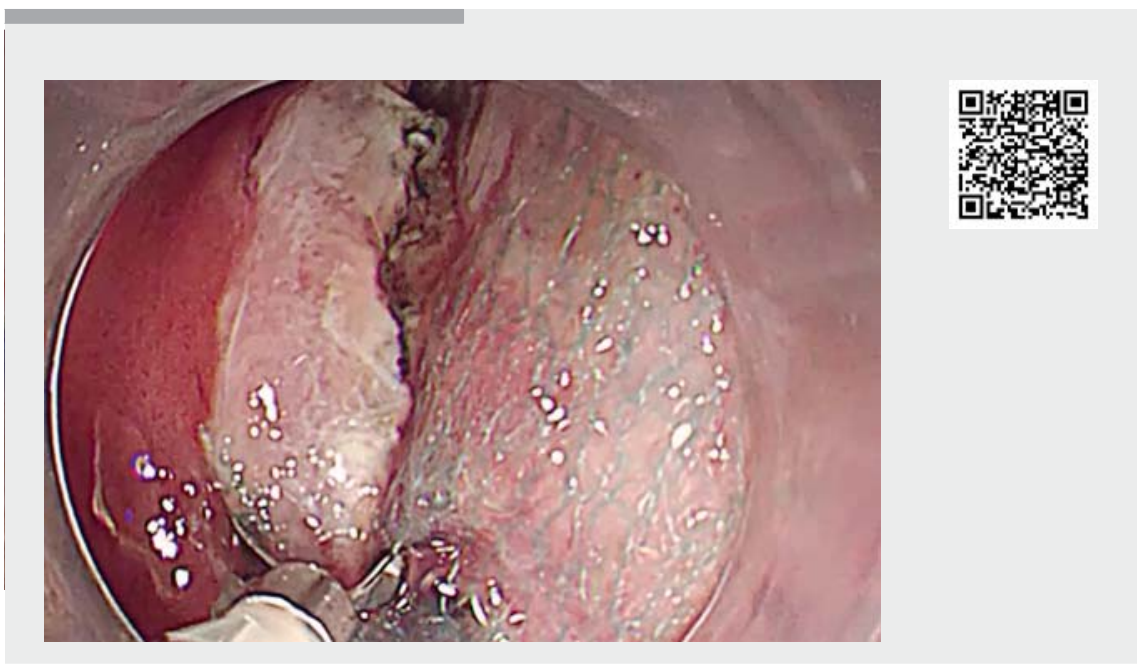

Video 1 The polyglycolic acid sheets, fibrin glue, and modified search, coagulation, and clipping (PMSCC) method for prevention of delayed bleeding in a high risk patient.

\section{Corresponding author}

\section{Satoshi Abiko}

Department of Gastroenterology, Kushiro Rosai Hospital, 13-23 Nakazono-cho, 0858533 Kushiro, Japan

Fax: +81-154-25-7308

abiko1982@gmail.com

\section{References}

[1] Azumi M, Takeuchi M, Koseki Y et al. The search, coagulation, and clipping (SCC) method prevents delayed bleeding after gastric endoscopic submucosal dissection. Gastric Cancer 2019; 22: 567-575

[2] Kawata N, Ono H, Takizawa K et al. Efficacy of polyglycolic acid sheets and fibrin glue for prevention of bleeding after gastric endo- scopic submucosal dissection in patients under continued antithrombotic agents. Gastric Cancer 2018; 21: 696-702

[3] Kataoka Y, Tsuji Y, Hirasawa K et al. Endoscopic tissue shielding to prevent bleeding after endoscopic submucosal dissection: a prospective multicenter randomized controlled trial. Endoscopy 2019; 51: 619-627

[4] Kobayashi N, Mori H, Kobara H et al. Reliable procedure of polyglycolic acid sheet delivery and placement on gastric artificial floor: Application of wafer paper and thread. Dig Liver Dis 2018; 50: 724

[5] Takimoto K, Toyonaga T, Matsuyama K. Endoscopic tissue shielding to prevent delayed perforation associated with endoscopic submucosal dissection for duodenal neoplasms. Endoscopy 2012; 44: E414-E415

\section{Bibliography}

DOI https://doi.org/10.1055/a-1122-8541

Published online: 18.3.2020

Endoscopy 2020; 52: E344-E345

(c) Georg Thieme Verlag KG

Stuttgart · New York

ISSN 0013-726X

\section{ENDOSCOPY E-VIDEOS}

https:/|eref.thieme.de/e-videos

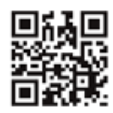

Endoscopy E-Videos is a free access online section, reporting on interesting cases and new techniques in gastroenterological endoscopy. All papers include a high quality video and all contributions are freely accessible online.

This section has its own submission website at https://mc.manuscriptcentral.com/e-videos 